\title{
Meta-Analysis of Constraint-Induced Language Therapy in Aphasia
}

\author{
Sae Mi Hong, ${ }^{\mathrm{a}, \mathrm{b}}$, Jin Kyung Kang ${ }^{\mathrm{b}}$, Bora Eom ${ }^{\mathrm{b}}$, Young Tae Kim ${ }^{\mathrm{b}}$, Jee Eun Sung ${ }^{\mathrm{b}}$, Hyun Sub Sim ${ }^{\mathrm{b}}$, Pil Yeon Jeong ${ }^{\mathrm{b}}$ \\ ${ }^{a}$ Department of Rehabilitation Medicine, Asan Medical Center, Seoul, Korea \\ ${ }^{b}$ Department of Communication Disorders, Ewha Womans University, Seoul, Korea
}

Correspondence: Young Tae Kim, PhD Department of Communication Disorders, Ewha Womans University, 52 Ewhayeodae-gil, Seodaemun-gu, Seoul 03760, Korea

Tel: +82-2-3277-2410

Fax: +82-2-3277-2122

E-mail: youngtae@ewha.ac.kr

Received: December 31, 2015

Revised: February 2, 2016

Accepted: February 9, 2016

This work was supported by the Brain Korea 21 (BK 21) Plus Project funded by the Ministry of Education, Korea.

\begin{abstract}
Objectives: Constraint-Induced Language Therapy (CILT) is an aphasia treatment program which comprises forced use of verbal language and massed practice. There are many studies about the efficacy of CILT on aphasia, but the results are controversial. Thus, the purpose of the present meta-analysis study was to systematically evaluate the effects of CILT for aphasia and to establish the evidence-based practice of CILT. Methods: Data collection was performed from 5 databases (DBPIA, EBSCOhost, ProQuest, PubMed, RISS) which were about CILT for aphasia. Nine studies which met the inclusive criteria were entered into the meta-analysis. Effect sizes for each study outcome (standardized language test outcome) were calculated. Results: There were two main findings from the current study. First, the meta-analysis results indicated that CILT is an effective treatment method for improving both overall language ability and each sub-language area. Second, CILT was effective for both chronic aphasia and acute aphasia-overall and in each sub-language area. Conclusion: The present study suggests the comprehensive effectiveness of CILT for aphasia in each sub-language area including auditory comprehension, repetition, and naming, and its treatment effectiveness for both chronic aphasia and acute aphasia regardless of post onset time. This research unifies the complicated results of previous studies and lays the foundation for clinical implications.
\end{abstract}

Keywords: Aphasia, CILT, Meta-analysis
실어증은 후천적인 뇌손상에 기인하여 언어 기능이 저하된 상태 를 말한다(McNeil \& Pratt, 2001). 최근 대두되고 있는 실어증 치료 기법으로는 Constraint-Induced Language Therapy (CILT)가 있 다. CILT 중재는 뇌가 경험에 의해 변화되는 원리인 신경가소성 (neuroplasticity) 원리에 기반을 둔 중재 방법으로, 실어증 환자들 이 손상된 의사소통능력을 보완하기 위해 사용하는 비구어 보상 전략이 구어 사용의 기회를 제한하고 구어 회복을 방해한다는 전 제 하에 집중적인 구어 사용을 치료에 적용시킨 것이다(Kleim \& Jones, 2008).

Constraint-induced (CI) 기반의 치료적 접근은 학습된 비사용 (learned non-use)을 예방하기 위해 손상된 부위를 높은 강도로 사 용하는 것을 원칙으로 하여 실어증 환자에게 적용하기 전 Constraint-Induced Movement Therapy (CIMT)라는 명칭으로 편마
비 환자들의 운동재활에 먼저 적용되었고(Visintin, Barbeau, Korner-Bitensky, \& Mayo, 1998), 20년이 넘는 기간 동안 여러 연구들 을 통해 중재 효과에 대한 증거 기반을 마련하였다(Mark, Taub, \& Morris, 2006).

전통적인 치료기법이 효과적인 의사소통을 위해 사진, 그림 그리 기, 쓰기 혹은 제스처와 같은 다중 양식 체계의 사용을 권장하는 반면, CILT 중재는 다양한 의사소통전략 중 구어 사용을 강조하 고, 구어 기능 향상을 위해 비구어 보상전략 사용을 지양한다. 또한 소그룹을 구성하여 평균적으로 하루 3 시간씩, 일주일에 5 일이라는 강도 높은 일정(massed practice) 동안 점진적인 행동 형성(shaping)의 절차를 따른다(Raymer, 2009).

일반적으로 뇌졸중 발병 후 6 개월 이내에는 언어기능의 자연 회 복이 이루어지는 반면, 발병 후 1 년이 경과한 만성 실어증 환자의 
경우에는 자연 회복 및 치료를 통한 언어기능의 향상이 제한적인 것으로 알려져 왔다(Kertesz, 1984). 하지만 Pulvermüller 등(2001) 은 $\mathrm{CI}$ 기반의 집중적인 언어 중재를 발병기간이 평균 8 년 이상인 10 명의 만성 실어증 환자들에게 처음으로 적용하였고, 그 결과 하루 3-4시간씩 10일이라는 짧은 기간 동안의 CILT 중재가 만성 실어증 환자들의 언어능력을 향상시키는 데 효과적임을 보고하였다. 또한 통제집단에게 전통적인 실어증 중재(conventional language therapy)를 적용하여 두 가지 중재방법의 효과를 비교한 결과 CILT 중재 가 전통적인 실어증 중재보다 실어증 환자의 언어능력 향상에 더 효과적이라는 결과를 보고하였다.

Pulvermüller 등(2001)에 의해 집중적인 일정의 CI 기반 언어중 재가 실어증 환자에게 처음으로 적용된 이래로 CILT 중재 원리와 효과에 관한 여러 연구들이 지속적으로 시행되어 왔으나 CILT 중 재 효과에 대해서는 다양한 결과들이 보고되었다.

Maher 등(2006)은 만성 실어증 환자를 대상으로 CILT와 전통적 인 실어증 치료기법인 Promoting Aphasic Communicative Effectiveness (PACE) 중재(Davis \& Wilcox, 1985)를 각각 적용한 결과, CILT 중재가 구어 산출에 더 효과적이며, 1 개월 후 실시한 유지평 가에서도 그 효과성이 유지된다는 결과를 보고하였다. Kurland, Pulvermüller, Silva, Burk와 Andrianopoulos (2012)도 CILT 중재 가 만성 비유창성 실어증 환자의 이름대기 능력 향상에 $\mathrm{PACE}$ 중재 보다 더 효과적이라는 결과를 보고하였다. 국내에서는 Han, Sung, Kim과 Cheon (2012)이 한국어의 특성을 고려한 CILT 중재가 만 성 비유창성 실어증 환자의 전반적인 언어능력 향상에 효과적임을 보고하였다.

많은 연구들이 CILT 중재의 긍정적인 효과성을 입증하였지만, 언어의 하위 영역에 따라 서로 다른 효과크기를 나타냈으며, 각 영 역에서의 효과 여부는 연구마다 상이하였다. Pulvermüller 등(2001) 과 Pulvermüller, Hauk, Zohsel, Neininger와 Mohr (2005)의 연구 에서는 CILT 중재가 만성 실어증 환자의 청각적 이해력과 이름대 기 영역에서 유의한 향상을 나타낸 반면, 따라말하기에서는 유의 한 향상을 나타내지 않았으며, Han 등(2012)의 연구에서는 스스로 말하기와 이름대기에서만 유의한 향상이 나타났고, 청각적 이해력 과 따라 말하기에서는 통계적으로 유의한 향상을 확인할 수 없었 다. Szaflarski 등(2008)은 CILT 중재가 실어증 환자의 청각적 이해 력 향상에는 효과적이지만, 표현 언어 향상에는 효과적이지 않다 고 보고하였다. 16 명의 실어증 환자에게 하루에 3 시간씩 10 일 동안 CILT 중재를 실시한 Richter, Miltner와 Straube (2008)도 CILT 중 재가 실어증 환자의 언어능력 향상에 긍정적이지만, 언어의 하위 영역에 따라 효과크기가 다르며, Aachen Aphasia Test (AAT; Hu- ber, Poeck, Weniger, \& Willmes, 1983) 검사의 하부검사인 Token Test 검사상에서는 유의한 효과가 없다는 결과를 제시하였다.

CILT 중재가 실어증 환자의 언어능력 향상에 효과적이지 않다 는 상반된 연구 결과도 지속적으로 보고되어 왔다. Goral과 Kempler (2009)는 1명의 만성 비유창성 실어증 환자에게 CILT 중재를 실시한 결과 Boston Diagnostic Aphasia Examination (BDAE; Goodglass, Kaplan, \& Baressi, 2000)상에서 중재 전과 비교 시 유 의한 변화가 없었으며, 이야기 과제에서 동사사용의 빈도는 유의하 게 증가했지만, 명사 사용은 증가하지 않았다고 하였다. Naeser 등 (2010)은 반복적 경두개 자기자극술(repetitive transcranial magnetic stimulation)과 CILT 중재가 비유창 실어증 환자의 평균발화 길이(mean length of utterance)에 유의한 영향을 미치지 않는다고 하였다.

Rose (2013)는 CILT 중재가 다중 양식 체계를 허용하는 기존의 전통 치료기법과 그 효과성이 동등하며, 아직까지 CILT 중재의 효 과성을 강력하게 지지할 만한 증거가 불충분하다고 하였다.

이와는 다르게 지난 10 년간 실어증 환자들의 언어재활을 위해 CILT 중재를 적용한 연구들을 종합적으로 분석한 Meinzer, Rodriguez와 Rothi (2012)는 CILT 중재가 실어증 환자에게 유용하다 는 결과를 지지하였으며, CILT 중재가 만성 실어증 환자뿐만 아니 라 급성 실어증 환자들의 언어능력 향상에도 효과적이라고 하였다. 하지만 대부분의 연구가 만성 실어증 환자들을 대상으로 CILT 중 재의 효과성을 입증한 반면, 급성 실어증 환자들을 대상으로 CILT 중재를 적용한 연구는 상대적으로 적었기 때문에 연구의 결과를 일반화하기에는 제한적이라고 하였다.

이처럼 많은 연구들이 CILT 중재의 효과를 검증하였지만 다양 한 결과를 나타냈으며, 기존에 CILT 중재 효과를 살펴본 연구들에 대한 종합적인 분석은 개별 연구들의 통계적인 검정 결과를 종합 한 효과크기(effect size) 측정이 이루어지지 않았기 때문에 CILT 중 재가 실어증 환자에게 유용한 치료기법이라는 결론을 도출하는 것 에는 제한이 따른다. 따라서 CILT 중재의 효과성에 대한 통합된 결 론을 도출하여 증거기반 실제를 구축하는 것이 필요하다.

중재의 효과성을 검증하기 위해 실시하는 대표적인 방법으로는 각각의 연구 결과를 통계적인 절차를 통해 종합하고 분석하여 통 합된 결론을 도출하는 메타분석이 있다(Borenstein, Hedges, Higgins, \& Rothstein, 2009).

본 연구는 메타분석 절차에 따라 CILT 중재 효과성을 살펴본 국 내외 개별 연구들을 수집하여 효과크기를 분석하고 결과를 종합 해 CILT 중재가 실어증 환자의 전반적인 언어능력 및 언어의 하위 영역에 미치는 효과를 알아보고자 한다. 나아가 실어증 발병기간 
에 따른 효과크기를 비교 분석하여 일반화된 결론을 도출하고자 한다. 구체적인 연구 질문은 다음과 같다.

첫째, CILT 중재는 실어증 환자의 전반적인 언어능력 향상에 효 과를 나타내는가?

둘째, CILT 중재는 언어 하위 영역(청각적 이해력, 따라 말하기, 이름대기)에 따라 다른 효과를 나타내는가?

셋째, CILT 중재는 실어증 발병기간(급성 실어증, 만성 실어증) 에 따라 실어증 환자의 전반적인 언어능력 및 언어 하위 영역 향상 에 다른 효과를 나타내는가?

\section{연구 방법}

\section{문헌검색}

실어증 환자들을 대상으로 실시한 CILT 중재의 효과를 살펴보 기 위해 2015년 10월에 국내(DBPIA, RISS) 2개, 해외(EBSCOhost, ProQuest, PubMed) 3개, 총 5개의 데이터베이스에서 문헌검색을 실시하였다.

문헌검색을 위해 사용한 검색어는 'aphasia' and 'constraint induced language therapy' or 'constraint induced language treatment' or 'CILT'로 하였다.

\section{문헌선정}

PubMed에서 59편, ProQuest에서 50편, EBSCOhost에서 31편, RISS에서 8편, DBPIA에서 0 편, 총 148 편의 연구가 검색되었다. 우 선 각 데이터베이스에서 검색한 문헌 중 중복된 문헌 9편을 제외하
였다. 다음으로 연구 제목과 초록을 통해 CILT와의 관련성 여부를 확인하였고, 그 결과 실어증 치료기법인 CILT와 관련이 없는 연구 69편을 추가로 제외하였다. 또한 연구 대상이 실어증 환자가 아닌 연구 2편을 제외하였고, 연구 설계에 따라 리뷰연구 6 편, 단일대상 연구 5편을 제외하였다. 그룹 내 사전-사후 비교 연구와 그룹 간 비 교 연구 중 CILT를 적용한 집단 내 사전-사후를 비교한 연구는 선 정에 포함하였다. 연구의 출판형태가 학위논문, 단행본에 해당하 는 27편을 제외하였으며, 연구 전문 확인이 불가능한 5 편도 선정에 서 제외하였다. 연구 전문 확인 결과 실어증 환자를 대상으로 CILT 를 적용하기 전과 적용 후를 비교하였지만 측정 방법이 표준화된 언어검사도구를 사용하지 않은 경우와 측정 결괏값을 제시하지 않 은 경우에 해당되는 16 편의 연구를 선정에서 제외하였다. 결론적 으로 실어증 환자의 CILT 중재 효과 측정을 위해 한 가지 이상의 언 어검사를 사용하고, 사전-사후 검사 결괏값을 제공한 9편의 연구 가 선정되었다. 논문의 선정 기준 및 선정 과정은 Figure 1과 같다.

\section{연구의 질 평가}

연구의 질적 평가를 위해 Gersten 등(2005)의 필수 질적 지표를 참고하여 1점 '부적절’에서부터 3점 '적절'까지 3점 척도로 평가하 였다. 연구대상에 대한 정보, CILT 중재 방법, 중재의 목적과 관련 된 결과의 측정 등을 분석한 결과 9 개의 논문이 모든 항목에서 적 절한 것으로 평가되어 평균 3 점으로 평가되었다.

\section{자료의 코딩}

메타분석을 위해 선정한 연구들을 연구자, 출판연도, 연구대상

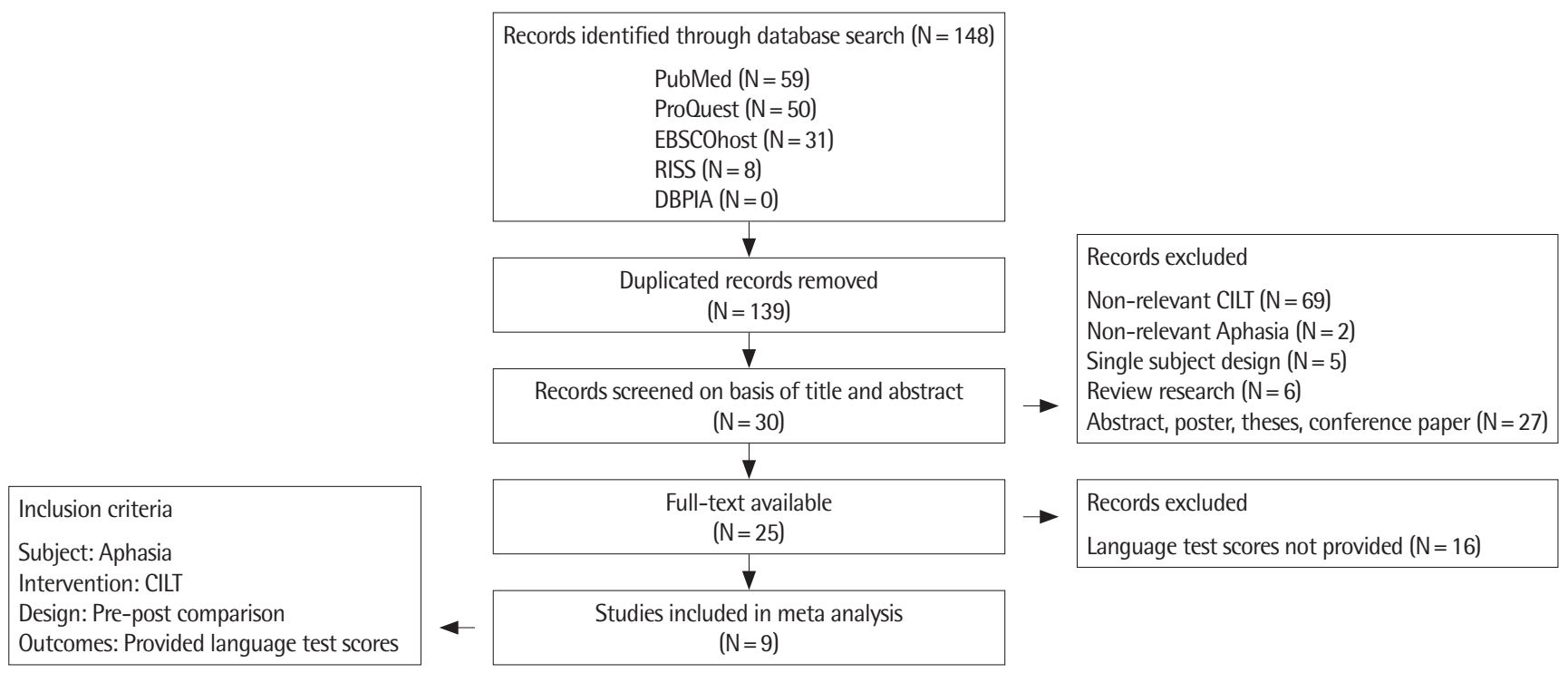

Figure 1. Flowchart of studies included from database search. CILT=Constraint-Induced Language Therapy. 


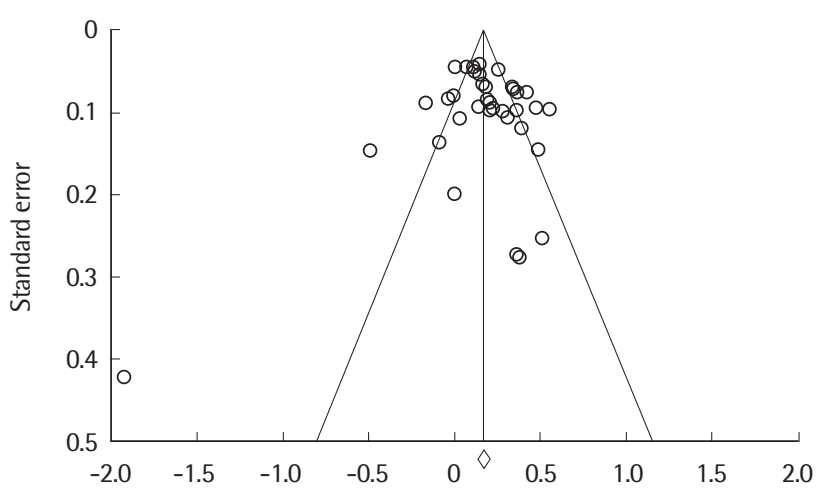

Figure 2. Funnel plot of standard error by Hedges's $g$.

의 유형, 연구대상의 수, 독립변인(CILT), 종속변인(언어평가 결과) 의 통계값( $\mathrm{M}, \mathrm{SD}, r$ 값, $p$ 값)으로 분류하여 코딩을 하였다.

\section{신뢰도 평가}

언어병리학 박사학위과정 중인 3 명의 연구자가 전체연구에 해당 되는 9편의 연구를 다시 코딩 후 효과크기를 산출하여 각 항목별 로 일치한수의 비율을 측정한 결과, 일치율은 $100 \%$ 였다.

\section{통계분석}

메타분석을 위한 통계 프로그램인 CMA2 (Comprehensive Meta-Analysis version 2)를 사용하여 코딩한 자료에 대한 메타분석을 실시하였다. 메타분석을 위해서는 Hedges's $g$ 로 평균효과크기를 산출하였다.

\section{출판 편향 검증}

출판 편향(publication bias)을 살펴보기 위해 Funnel plot을 확 인한 결과 Funnel plot의 형태가 대칭적이었으며(Figure 2), Egger의 회귀분석을 확인한 결과 출판편향이 없는 것을 확인할 수 있었다 ( $p>.05)$.

\section{연구 결과}

\section{질적분석}

본 연구에 포함된 논문은 총 9편이었다. 연구대상은 총 105 명의 실어증 환자였으며, 한 연구에 참여한 대상자는 최소 3 명부터 최대 50 명까지였고, 2 편을 제외한 연구들의 대상자는 모두 10 명 미만이 었다. 대상 연령 분포는 48세-72.67세였고, 실어증 발병기간은 최소 1.5 개월부터 최대 88.88 개월까지였으며, 3 편의 연구는 급성 실어증 환자를 대상으로, 6 편의 연구는 만성 실어증 환자를 대상으로 하였
다. 연구대상의 실어증 유형은 연구마다 실어증을 구분한 방법에 차이가 있었다. 일부 연구들은 실어증 유형을 비유창성 실어증과 유창성 실어증으로만 구분한 반면, 일부 연구들은 뇌의 기능적인 부분에 따라 유형을 세분화 한 보스턴 학파의 기준에 따라 나누기 도 하였다. 한 연구는 실어증 유형을 구분하지 않고 연구 대상을 좌 반구 손상의 뇌졸중으로 기인한 중도 실어증 환자라고만 명시하기 도 하였다. 실어증 중증도는 경도부터 고도까지 다양하였으며, 중 증도를 언급하지 않은 연구들도 있었다.

CILT 중재를 실시한 횟수는 평균 10회(범위: 8-12회)였고, 한 회 기당 시간은 평균 165.5 분(범위: 119.5 분-240분)이었다. 중재 기간 은 평균 13.88 일(범위: 10-21일)이었다.

CILT 중재의 효과를 측정하기 위해 사전-사후 검사에 사용된 표 준화된 검사도구는 언어의 전반적인 능력을 측정하는 도구와 언어 의 각 하위 영역을 측정하는 도구가 있었다. 전반적인 언어능력을 측정하는 도구에는 AAT (Graetz, De Bleser, \&Willmes, 1992; Huber et al., 1983), Boston Diagnostic Aphasia Battery (Goodglass \& Kaplan, 1972), Norwegian Basic Aphasia Assessment (Reinvang \& Engvik, 1980; Reinvang, 1985), Psycholinguistic Assessments of Language Processing in Aphasia (Kay, Lesser, \& Coltheart, 2009), Western Aphasia Battery (Kertesz, 1982; Kim \& Na, 2001) 등이 있 었다. 특정 언어 영역만을 측정하는 도구에는 청각적 이해력을 측 정하는 Test for Reception of Grammar (Bishop, 2009), Token Test (De Renzi \& Vignolo, 1962), 이름대기를 측정하는 Action Naming Test (Nicholas, Obler, Albert, \& Goodglass, 1985), Boston Naming Test (Kaplan, Goodglass, \& Weintraub, 1983, 2001; Kim \& Na, 1997; Marien, Mampaey, Vervaet, Saerens, \& De Deyn, 1998) 등이 있었 다. 일부 연구들은 언어 전반을 측정하는 도구를 사용하여 언어의 특정 하위 영역만을 측정한 경우도 있었다. 개별 연구의 특성은 Appendix 1에 요약하여 제시하였다.

\section{메타분석}

CILT 중재가 실어증 환자의 전반적인 언어능력에 미치는 효과

CILT 중재가 실어증 환자의 전반적인 언어능력 향상에 미치는 효과에 대한 메타분석 결과는 Figure 3과 같다. 효과크기 $g=.193$, $p<.01,95 \%$ 신뢰구간 $[0.133,0.253]$ 으로 CILT 중재가 실어증 환자 의 전반적인 언어능력 향상에 유의한 효과가 있는 것으로 나타났 다(Table 1).

CILT 중재가 실어증 환자의 언어 하위 영역에 미치는 효과 CILT 중재가 실어증 환자의 언어 하위 영역인 청각적 이해력, 따 
Study name

Breier et al. $(2000)$ a

Breier et at. $(2000) \mathrm{b}$

Breigr et al. $(2000) 0$

Breier et al. $(2000) d$

Han et al. (2012)a

Han et al. (2012)b

Han et al. $(2012) e$

Han et al. (2012)d

$H$ an et al. $(2012)$ e

Krmess \& Lind (2011)?

Kirmess \& Lind 2011$) b$

Kirmes s \& Lind 2011)

Kirmess \& Lind (2011)d

Kirmess \& Lind 2011)

Kirmes s \& Mbher(2010)a

Kirmess \& Mbher(2010)b

Kirmess \& Maher(2010)c

Krmess \& Mbher(2010)d

Moner et al . (2006)9

Maher et al $(2000) b$

Maher et al . $(2006) 0$

Meinser et al (2007)a

Meinzer et al (2007)b

Meinser of al (2007)0

Meinser et al (2007)d

Meinser ef al (2007)e

Mohr et al (2014)a

Morr et: al $(2014) b$

Mohr et al (2014)c

Siokert et al (20 14)a

Sidiert et al (20 14)b

Sidiert et al (2014)o

Sidkert et al (20 14)d

Wiksers et al (2015)a

Wibsers et al. (2015)b

Wibsers et al (2015)e

Wibsers et al. (2015)d

Wiksers et al (2015)e
Outcome

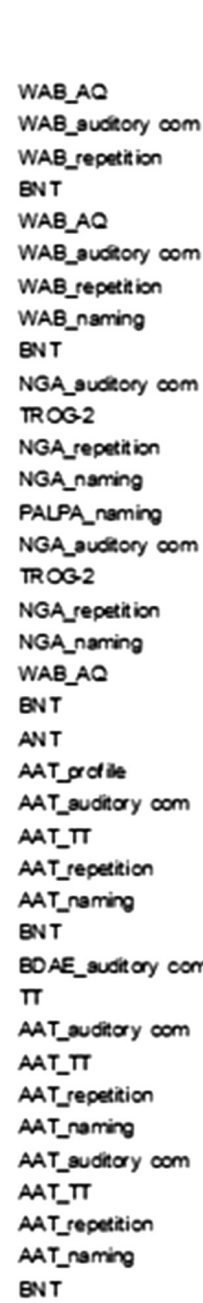

Statistics for each study

Hedges's Lower Upper

9 limit limit Z-Value p-Value

$\begin{array}{lllll}-0.084 & -0.354 & 0.186 & -0.610 & 0.542\end{array}$

$\begin{array}{llllll}0.030 & -0.183 & 0.243 & 0.274 & 0.784\end{array}$

$\begin{array}{llllll}0.000 & -0.393 & 0.393 & 0.000 & 1.000\end{array}$

$\begin{array}{lllll}-0.033 & -0.196 & 0.130 & -0.394 & 0.094\end{array}$

$\begin{array}{lllll}0.287 & 0.091 & 0.483 & 2806 & 0.004\end{array}$

$\begin{array}{lllll}0.383 & -0.173 & 0.900 & 1.327 & 0.184\end{array}$

$\begin{array}{llllll}0.204 & 0.010 & 0.397 & 2064 & 0.039\end{array}$

$\begin{array}{lllll}0.191 & 0.024 & 0.358 & 2238 & 0.025\end{array}$

$\begin{array}{lllll}0.178 & 0.042 & 0.314 & 2560 & 0.010\end{array}$

$\begin{array}{llllll}0.000 & -0.158 & 0.158 & 0.000 & 1.000\end{array}$

$\begin{array}{llllll}0.105 & 0.013 & 0.198 & 2241 & 0.025\end{array}$

$\begin{array}{lllll}0.141 & 0.045 & 0.327 & 1.488 & 0.137\end{array}$

$\begin{array}{lllll}0.225 & 0.035 & 0.415 & 2320 & 0.020\end{array}$

$\begin{array}{llllll}0.349 & 0.209 & 0.490 & 4800 & 0.000\end{array}$

$\begin{array}{lllll}0.010 & 0.081 & 0.101 & 0.215 & 0.830\end{array}$

$\begin{array}{lllll}0.084 & 0.028 & 0.156 & 1.388 & 0.171\end{array}$

$\begin{array}{llllll}0.185 & 0.033 & 0.297 & 2454 & 0.014\end{array}$

$\begin{array}{lllll}0.255 & 0.159 & 0.351 & 5.218 & 0.000\end{array}$

$\begin{array}{lllll}0.313 & 0.102 & 0.524 & 2913 & 0.004\end{array}$

$\begin{array}{lllll}0.122 & 0.020 & 0.223 & 2350 & 0.019\end{array}$

$\begin{array}{lllll}0.142 & 0.040 & 0.243 & 2729 & 0.008\end{array}$

$\begin{array}{lllll}0.142 & 0.057 & 0.227 & 3283 & 0.001\end{array}$

$\begin{array}{lllll}0.386 & 0.205 & 0.507 & 4.831 & 0.000\end{array}$

$\begin{array}{lllll}0.335 & 0.198 & 0.472 & 4.788 & 0.000\end{array}$

$\begin{array}{lllll}0.421 & 0.209 & 0.574 & 5.412 & 0.000\end{array}$

$\begin{array}{lllll}0.386 & 0.171 & 0.581 & 3683 & 0.000\end{array}$

$\begin{array}{lllll}0.203 & 0.027 & 0.380 & 2.258 & 0.024\end{array}$

$\begin{array}{lllll}0.512 & 0.014 & 1.010 & 2017 & 0.044\end{array}$

$\begin{array}{lllll}-0.169 & -0.345 & 0.007 & -1.887 & 0.059\end{array}$

$\begin{array}{llllll}0.487 & 0.198 & 0.7 \pi & 3.304 & 0.001\end{array}$

$\begin{array}{lllll}-0.487 & -0.77 & -0.198 & -3.304 & 0.001\end{array}$

$\begin{array}{lllll}0.487 & 0.198 & 0.777 & 3.304 & 0.001\end{array}$

$\begin{array}{lllll}0.487 & 0.198 & 0.777 & 3.304 & 0.001\end{array}$

$\begin{array}{llllll}0.380 & 0.164 & 0.003 & 1.300 & 0.171\end{array}$

$\begin{array}{lllll}-1.921 & -2.750 & -1.092 & .4 .541 & 0.000\end{array}$

$\begin{array}{llllll}0.391 & 0.158 & 0.025 & 3264 & 0.001\end{array}$

$\begin{array}{lllll}0.471 & 0.285 & 0.087 & 4.959 & 0.000\end{array}$

$\begin{array}{lllll}0.562 & 0.380 & 0.743 & 5.857 & 0.000\end{array}$

$\begin{array}{lllll}0.193 & 0.133 & 0.253 & 6.347 & 0.000\end{array}$

\section{Hedge s's $\mathrm{g}$ and $95 \% \mathrm{Cl}$}
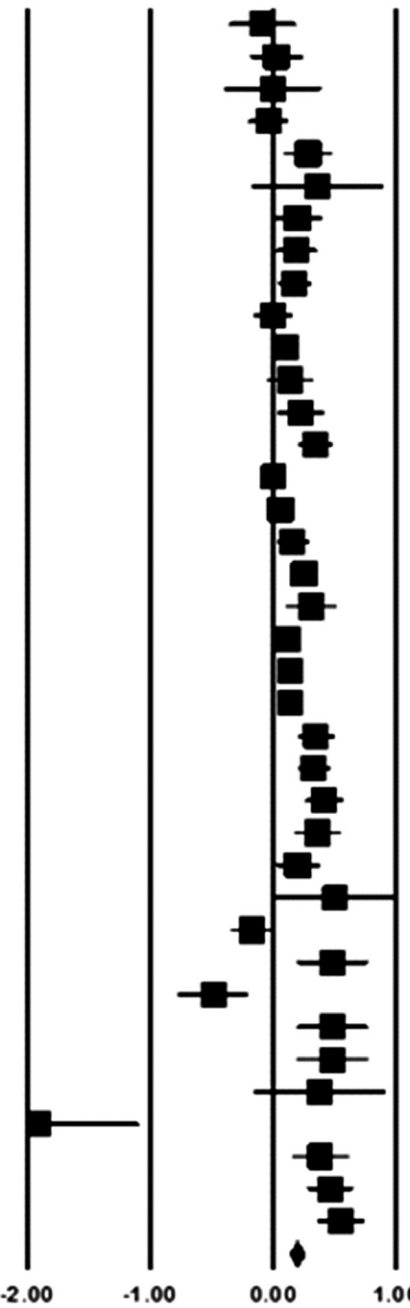

2.00

pre

post

Figure 3. Meta-analysis of the effectiveness of Constraint-Induced Language Therapy on overall language ability.

Table 1. The effectiveness of CILT on overall language ability for patients with aphasia

\begin{tabular}{lccc}
\hline Type & Hedges's $g$ & $95 \%$ Cl [LL, UL] & $p$ \\
\hline Overall & .193 & {$[.133, .253]$} & .000
\end{tabular}

CILT=Constraint-Induced Language Therapy; $\mathrm{Cl}=$ confidence interval; $\mathrm{LL}=$ lower limit; UL= upper limit.

라 말하기, 이름대기에 미치는 효과에 대한 메타분석 결과는 Table 2 와 같다. 청각적 이해력에서 $g=.089, p<.01,95 \%$ 신뢰구간[.047, $.130]$, 따라 말하기에서 $g=.260, p<.01,95 \%$ 신뢰구간[.188, .332], 이름대기 영역에서 $g=.226, p<.01,95 \%$ 신뢰구간[.186, .265]로
Table 2. The effectiveness of CILT on sub-language abilities for patients with aphasia

\begin{tabular}{lccc}
\hline Type & Hedges's $g$ & $95 \%$ CI [LL, UL] & $p$ \\
\hline Auditory comprehension & .089 & {$[.047, .130]$} & .000 \\
Repetition & .260 & {$[.188, .332]$} & .000 \\
Naming & .226 & {$[.186, .265]$} & .000 \\
\hline
\end{tabular}

$\mathrm{CILT}=$ Constraint-Induced Language Therapy; $\mathrm{Cl}=$ confidence interval; $\mathrm{LL}=$ lower limit; UL = upper limit.

CILT 중재가 실어증 환자의 모든 언어 하위 영역 향상에 유의한 효 과가 있는 것으로 나타났다. 
발병기간에 따라 CILT 중재가 실어증 환자의 전반적인 언어능력 및 언어 하위 능력에 미치는 효과

발병기간에 따라 CILT 중재가 실어증 환자의 전반적인 언어능력 및 언어 하위 능력에 미치는 효과에 대한 메타분석 결과는 Table 3 과같다.

급성 실어증 환자의 전반적인 언어능력에서 $g=.137, p<.01,95 \%$ 신뢰구간[.099, .174]로 유의하였으며(Figure 4), 청각적 이해력에서 $g=.051, p<.05,95 \%$ 신뢰구간[.002, .099], 따라 말하기에서 $g=.197$, $p<.01,95 \%$ 신뢰구간[.096, .298], 이름대기 영역에서 $g=.289, p<$ $.01,95 \%$ 신뢰구간[.218, .360]으로 CILT 중재가 급성 실어증 환자의 모든 언어 하위 영역 향상에 유의한 효과가 있는 것으로 나타났다.

Table 3. The effectiveness of CILT on overall language ability for patients with aphasia by post onset time

\begin{tabular}{lccc}
\hline & Hedges's $g$ & $95 \%$ CI [LL, UL] & $p$ \\
\hline Acute aphasia group (N=3) & & & \\
$\quad$ Overall & .129 & {$[.090, .168]$} & .000 \\
$\quad$ Auditory comprehension & .051 & {$[.002, .099]$} & .042 \\
$\quad$ Repetition & .197 & {$[.096, .298]$} & .000 \\
$\quad$ Naming & .289 & {$[.218, .360]$} & .000 \\
Chronic aphasia group (N=6) & & & \\
$\quad$ Overall & .225 & {$[.187, .264]$} & .000 \\
$\quad$ Auditory comprehension & .186 & {$[.108, .264]$} & .000 \\
$\quad$ Repetition & .325 & {$[.222, .428]$} & .000 \\
$\quad$ Naming & .197 & {$[.149, .245]$} & .000 \\
\hline
\end{tabular}

$\mathrm{CILT}=$ Constraint-Induced Language Therapy; $\mathrm{Cl}=$ confidence interval; $\mathrm{LL}=$ lower limit; UL= upper limit.
만성 실어증 환자의 전반적인 언어능력에서 $g=.201, p<.01,95 \%$ 신뢰구간[.168, .234]로 유의하였으며(Figure 5), 청각적 이해력에서 $g=.186, p<.01,95 \%$ 신뢰구간[.108, .264], 따라 말하기에서 $g=.325$, $p<.01,95 \%$ 신뢰구간[.222, .428$]$, 이름대기 영역에서 $g=.197, p<.01$, $95 \%$ 신뢰구간[.149, .245]로 CILT 중재가 만성 실어증 환자의 모든 언어 하위 영역 향상에 유의한 효과가 있는 것으로 나타났다.

\section{논의 및 결론}

본 연구는 메타분석을 통해 실어증 환자를 대상으로 실시한 CILT 중재가 실어증 환자들의 전반적인 언어능력을 비롯하여 언어 의 하위 영역인 청각적 이해력, 따라 말하기, 이름대기에서 모두 유 의한 효과가 있다는 결과를 도출함으로써 기존의 개별적으로 보고 된 상이한 연구 결과를 통합할 수 있었다. 또한 CILT 중재의 유의 한 효과성은 실어증 발병기간과 무관하며, 급성 실어증과 만성 실 어증 집단 모두에서 유의한 것으로 나타났다.

이러한 결과는 CILT 중재가 실어증 환자에게 효과적이라고 보고 한 연구들의 결과와 일치하며(Cherney, Patterson, Raymer, Frymark, \& Schooling, 2010; Meinzer et al., 2012), 집중적인 중재 일정 동안 보상전략을 제한하고 구어를 극대화하여 사용할 수 있게 구조화한 방법이 실어증 환자들의 학습된 비사용(learned non-use)을 예방 하고 언어능력을 향상시키는 데 유용하다는 것을 뒷받침한다.

하지만 CILT 중재가 실어증 환자들의 언어능력 향상에 효과적
Study name

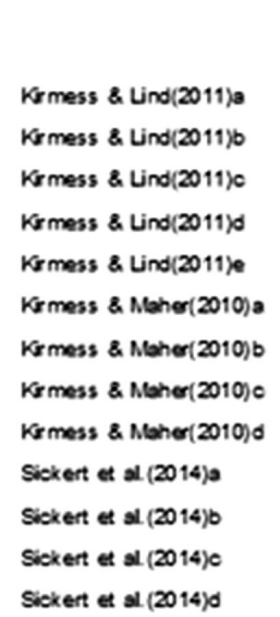

Outcome

NGA_auditory com
TROG-2
NGA_repetition
NGA_naming
PALPA_naming
NGA_auditory com
TROG-2
NGA_repetition
NGA_naming
AAT_auditory $\infty m$
AAT_TT
AAT_repetition
AAT_naming

\begin{tabular}{|c|c|c|c|c|}
\hline $\begin{array}{c}\text { Hedges's } \\
g\end{array}$ & $\begin{array}{c}\text { Lower } \\
\text { limit }\end{array}$ & $\begin{array}{c}\text { Upper } \\
\text { limit }\end{array}$ & Z-Value & p-Value \\
\hline 0.000 & -0.158 & 0.158 & 0.000 & 1.000 \\
\hline 0.105 & 0.013 & 0.196 & 2.241 & 0.025 \\
\hline 0.141 & .0 .045 & 0.327 & 1.488 & 0.137 \\
\hline 0.225 & 0.035 & 0.415 & 2.320 & 0.020 \\
\hline 0.349 & 0.209 & 0.490 & 4.800 & 0.000 \\
\hline 0.010 & -0.081 & 0.101 & 0.215 & 0.830 \\
\hline 0.004 & -0.028 & 0.158 & 1.368 & 0.171 \\
\hline 0.166 & 0.033 & 0.297 & 2.454 & 0.014 \\
\hline 0.256 & 0.159 & 0.351 & 5.218 & 0.000 \\
\hline 0.487 & 0.198 & $0.7 \pi 7$ & 3.304 & 0.001 \\
\hline-0.487 & -0.777 & -0.198 & .3 .304 & 0.001 \\
\hline 0.487 & 0.198 & $0.7 \pi$ & 3.304 & 0.001 \\
\hline 0.487 & 0.198 & $0.7 \pi$ & 3.304 & 0.001 \\
\hline 0.137 & 0.099 & 0.174 & $7.17 \pi$ & 0.000 \\
\hline
\end{tabular}

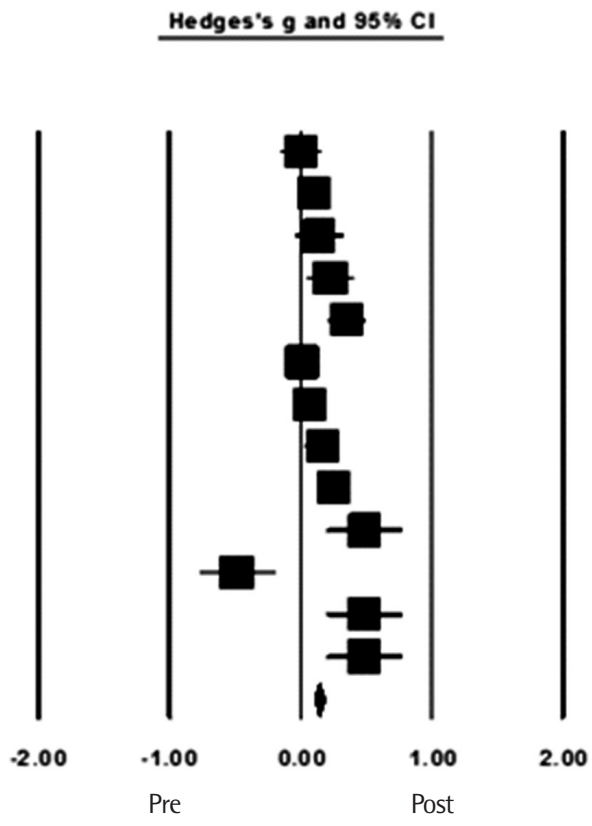

Figure 4. Meta-analysis of the effectiveness of Constraint-Induced Language Therapy on overall language ability for patients with acute aphasia. 


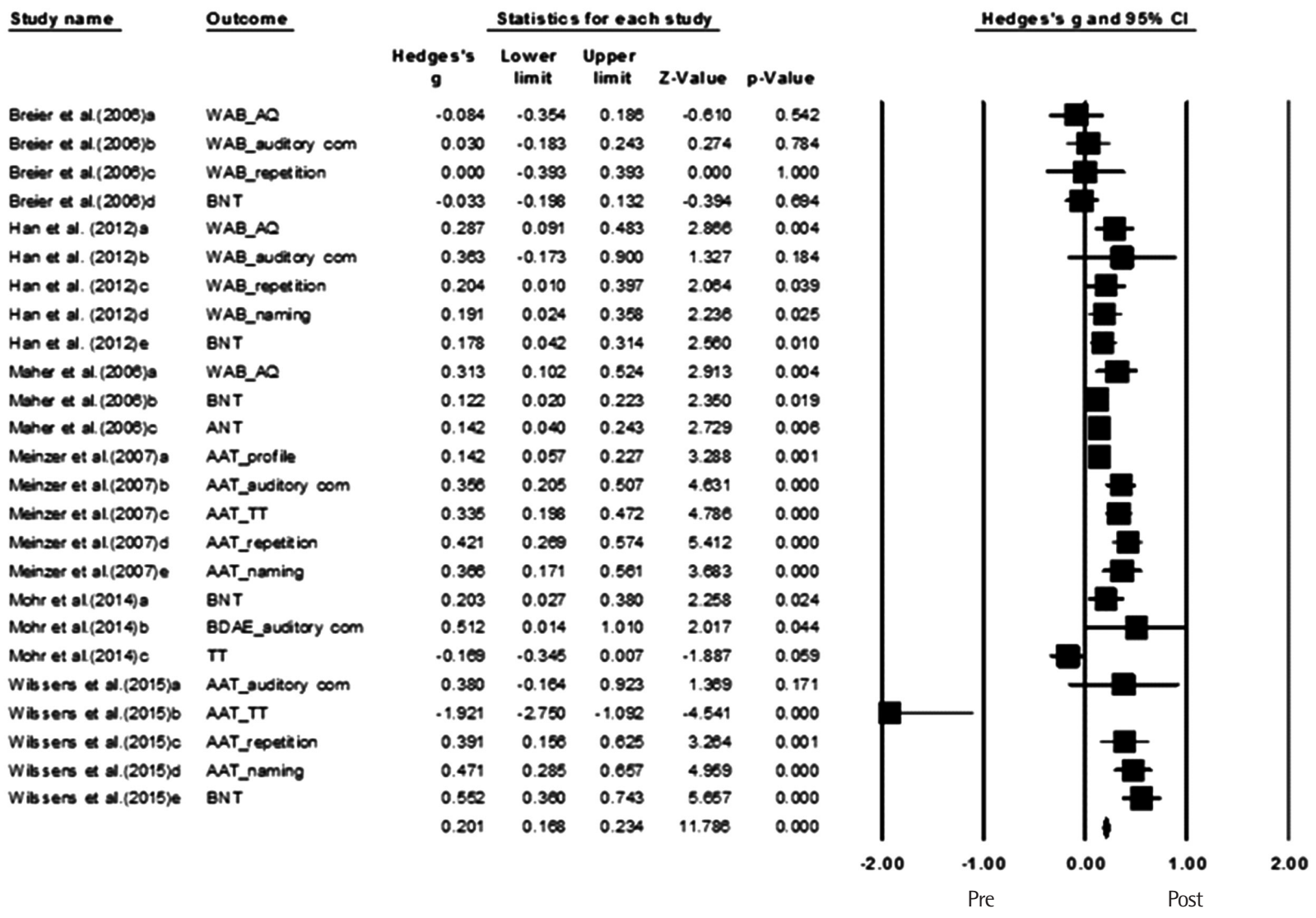

Figure 5. Meta-analysis of the effectiveness of Constraint-Induced Language Therapy on overall language ability for patients with chronic aphasia.

이지 않다는 연구들과는 상반된 결과를 나타낸다. 이는 연구 대상 자의 특성과 CILT 중재 효과를 측정하는 방법의 차이에서 기인한 것으로 추측된다.

본 연구는 급성 실어증 환자 56 명과 만성 실어증 환자 51 명을 대 상으로 실시되었으며, 실어증 유형은 다양하였다. CILT 중재가 효 과적이지 않았다는 기존 연구들(Goral \& Kempler, 2009; Naeser et al., 2010)의 특성을 살펴보면 대상자 수가 대부분 1-2명으로 개별 대상자의 변수가 미치는 영향을 배제하지 못했다는 제한점이 있다. 또한 담화능력에 대한 질적인 분석을 포함하였는데 본 연구에서는 CILT 중재의 효과를 측정하기 위해서 신뢰롭고 타당한 표준화된 검사도구만을 사용하였다는 데 차이가 있다.

본 연구에서는 CILT 중재가 실어증 환자의 전반적인 언어능력뿐 만 아니라, 청각적 이해력, 따라말하기, 이름대기에서 모두 유의한 효과가 있는 것으로 나타났다. CILT 중재는 구어 산출에 중점을 둔 중재 방법이라는 점에서 표현언어에 비해 수용언어에서는 상대적 으로 낮은 효과 크기를 나타내거나, 효과가 유의하지 않았다는 보 고들이 있었다(Han et al., 2012; Kirmess \& Maher, 2010; Richter et al., 2008). 하지만 본 연구에서는 청각적 이해력에서도 유의한 효과 가 있는 것으로 나타났다. 이는 CILT 중재 방법에 의한 것으로 추 측된다.

일반적으로 CILT 중재는 소그룹을 구성하여 장벽 게임(barrier game) 형태로 진행되며, 상대방에게 원하는 카드를 요청하는 구어 산출에 중점을 두게 된다. 하지만 상대방이 요구한 카드를 정확하 게 선택하고 제공하기 위해서는 청각적 이해력이 함께 요구된다. 따 라서 말 주고-받기(turn-taking)를 통해 이루어지는 CILT 중재 방 법이 표현언어뿐만 아니라, 자연스럽게 수용언어 촉진에도 영향을 미치게 되는 것이다.

또한 언어의 하위 영역별 중재 효과는 실어증 유형과도 밀접한 관련이 있을 수 있다. 이는 실어증 유형에 따라 각각의 언어 하위 영 역에서 다른 기초선(base line)을 나타내기 때문이다. 따라서 실어 증 유형에 따라 언어 하위 영역별로 효과를 검증하는 것이 필요하 다. 하지만 본 연구에서 분석한 9편의 문헌들 모두 실어증을 분류 하는 기준이 동일하지 않고, 연구 대상자의 개별 데이터를 제공하 지 않았기 때문에 추가적인 분석 및 논의에는 제한이 따른다. 
본 연구에서 CILT 중재의 효과성은 발병기간과 상관없이 급성 실어증과 만성 실어증 환자 모두에게 효과적인 것으로 나타났다. 지금까지 CILT 중재의 효과를 검증한 연구들은 대부분 만성 실어 증 환자들을 대상으로 하였고, 실제로 본 연구에서 분석한 9 개의 문헌 중 급성 실어증 환자들을 대상으로 한 문헌은 3편에 불과하였 으며, 모두 최근 몇 년 사이에 이루어진 연구들이었다.

Meinzer 등(2012)에 의하면 2001년부터 2010년간 급성 실어증 환자를 대상으로 CILT를 적용한 연구는 Kirmess와 Maher (2010) 의 연구 1 편뿐이었고, 대상자의 수 역시 3 명으로 통제집단과의 비 교 없이 사전-사후 검사로만 연구가 진행되었다는 제한점 때문에 결과를 일반화할 수 없었다. 이러한 이유로 CILT 중재 효과와 발병 기간에 따른 연구의 필요성은 지속적으로 제기되어왔다. 본 연구에 서는 Kirmess와 Maher (2010)의 연구 외에 두 편을 추가로 분석하 였으며, 대상자의 수 또한 총 56명으로 CILT 중재가 급성 실어증 환 자들에게 미치는 영향을 살펴보기 위한 통계적인 검정력을 높일 수 있었다.

이와 같이 본 연구에서는 발병기간에 따라 실어증 집단을 구분 하여 CILT 중재의 효과성을 검증하였다는 데 의의가 있다. 하지만 본 연구의 급성 실어증 집단의 평균 발병기간은 2 개월 이내로 실어 증의 자연회복이 활발하게 이루어지는 시기이다. 따라서 CILT 중 재 효과의 유의성을 해석할 때 자연회복의 가능성을 온전히 배제 하는 것에는 주의가 요구된다.

일반적으로 급성 실어증 환자들을 대상으로 특정 중재 효과를 검증하는 것에는 자연회복에 의한 영향력을 배제하지 못한다는 점 에서 제약이 따른다. 하지만 중재를 통한 언어능력의 향상이 모든 언어 하위 영역에서 동일하게 나타나지 않는다는 점에서 중재의 효 과를 자연회복에 의한 것이라 단정 짓기도 어렵다. 따라서 자연회 복의 영향성을 살펴보기 위해서는 환자가 결함을 보이는 모든 영역 에 대한 관찰이 필요하다(Poeck, Huber, \& Willmes, 1989). 본 연구 에서는 발병기간에 따른 집단 간 청각적 이해력, 따라 말하기, 이름 대기와 같이 다양한 언어 하위 영역에서의 효과를 검증하였고, 두 집단 모두 모든 영역에서 유의한 효과가 있다는 결과를 나타냈다.

회복에 영향을 미치는 주요한 요인으로는 병변의 크기와 실어증 의 중증도가 있다(Holland, 1989; Kertesz \& McCabe, 1977). 따라 서 이에 대한 통제가 이루어져야 하지만 본 연구에서 분석한 9편에 서는 개별 대상자의 중증도를 모두 언급하지 않았기 때문에 중증도 에 따른 CILT 중재의 효과 검증은 제한이 따른다.

본 연구는 메타분석을 통해 CILT 중재가 실어증 환자들에게 효 과적이라는 통합된 결론을 도출하였다는 데 의의가 있다. 하지만 통계적인 유의성에 대한 임상적 유효성을 고려해야 한다.
본 연구에 포함한 9편의 문헌에 대한 질적 분석을 통해 살펴본 CILT 중재는 약 2주간 주 5회씩 이루어졌으며, 한 회기당 평균 시간 이 3 시간 가까이였다. 이러한 집중적인 일정의 중재는 인력 부족 및 치료기관의 지원 등의 이유로 실제 임상에서 적용되기에는 제한적 일 것으로 보인다. CILT 중재 연구들의 대상자 수가 대부분 소수인 것도 이러한 이유 때문일 것이다. CILT 중재에 대한 치료 제공자의 의견을 조사한 Page와 Wallace (2014)는 연구에 참여한 167 명 중 $60 \%$ 이상이 CILT 중재의 강도 높은 일정에 대해 부정적이었으며, 회기당 시간을 축소하거나 일정을 변형하는 등의 조정이 불가피하 다고 하였다. 이처럼 CILT 중재의 효율성에 대한 추가적인 연구가 필요하다.

이를 위해서는 첫 번째로 CILT 중재 효과에 대한 유지를 확인할 필요가 있다. 본 연구에 포함된 문헌 중에서 사후 평가를 실시한 연 구는 1편에 불과하였다. CILT 중재가 실어증 환자들의 언어능력 향 상에 효과적이었다는 공통된 결과와는 다르게 사후 평가에서 효 과의 유지 여부는 연구에 따라 다른 결과를 나타냈다(Faroqi-Shah \& Virion, 2009; Kirmess \& Maher 2010). 따라서 이에 대해 통합된 결론을 도출하는 것이 필요하다.

두 번째로는 CILT 중재와 전통적인 치료기법에 대한 비교 분석 이 이루어져야 할 것이다. 본 연구에서는 CILT 중재의 효과성을 집 단 내 사전-사후 검사를 통해 독립적으로 측정하였지만, 집단 간 비 교에서 다중 양식 체계의 사용이 CILT 중재와 효과가 동등하거나 더 높다는 연구 결과들도 있기 때문이다(Attard, Rose, \& Lanyon, 2013; Barthel, Meinzer, Djundja, \& Rockstroh, 2008; Meinzer, Streiftau, \& Rockstroh, 2007).

끝으로 기능적 의사소통에 대한 측정이 고려되어야 할 것이다. CILT 중재 후 표준화된 검사상에서의 유의한 차이는 나타나지 않 지만 일상생활에서 환자 스스로 느끼는 질적인 변화는 분명 존재 할 가능성이 있다. 따라서 추후 CILT 중재의 효과 검증은 넓은 범 위에서 이루어져야 할 것이다.

\section{REFERENCES}

Attard, M. C., Rose, M. L., \& Lanyon, L. (2013). The comparative effects of Multi-Modality Aphasia Therapy and Constraint-Induced Aphasia Therapy-Plus for severe chronic Broca's aphasia: an in-depth pilot study. Aphasiology, 27, 80-111.

Barthel, G., Meinzer, M., Djundja, D., \& Rockstroh, B. (2008). Intensive language therapy in chronic aphasia: which aspects contribute most? Aphasiology, 22, 408-421. 
Bishop, D. V. M. (2009). Test for reception of grammar, version 2: TROG-2 manual (Norsk version). Bromma: Pearson Assessment.

Borenstein, M., Hedges, L. V., Higgins, J., \& Rothstein, H. R. (2009). Introduction to meta-analysis. Chichester: John Wiley \& Sons.

Breier, J. I., Maher, L. M., Novak, B., \& Papanicolaou, A. C. (2006). Functional imaging before and after constraint-induced language therapy for aphasia using magnetoencephalography. Neurocase, 12, 322-331.

Cherney, L. R., Patterson, J., Raymer, A., Frymark, T., \& Schooling, T. (2010). Updated evidence-based systematic review: effects of intensity of treatment and constraint-induced language therapy for individuals with stroke-induced aphasia. Retrieved from http://www.asha.org/uploadedFiles/EBSR-Updated-CILT.pdf

Comprehensive Meta-Analysis (Version 2) [Computer software]. Englewood, NJ: Biostat.

Davis, G. A., \& Wilcox, M. J. (1985). Adult aphasia rehabilitation: applied pragmatics. San Diego, CA: College-Hill Press.

De Renzi, E., \& Vignolo, L. (1962). The token test: sensitive test to detect receptive disturbances in aphasia. Brain, 85, 665-678.

Faroqi-Shah, Y., \& Virion, C. R. (2009). Constraint-induced language therapy for agrammatism: role of grammaticality constraints. Aphasiology, 23, 977988.

Gersten, R., Fuchs, L. S., Compton, D., Coyne, M., Greenwood, C., \& Innocenti, M. S. (2005). Quality indicators for group experimental and quasiexperimental research in special education. Exceptional Children, 71, 149164.

Goodglass, H., \& Kaplan, E. (1972). The assessment of aphasia and related disorders. Philadelphia, PA: Lea \& Febiger.

Goodglass, H., Kaplan, E., \& Baressi, B. (2000). Boston Diagnostic Aphasia Examination-third edition (BDAE-3). San Antonio, TX: Pearson.

Goral, M., \& Kempler, D. (2009). Training verb production in communicative context: evidence from a person with chronic non-fluent aphasia. Aphasiology, 23, 1383-1397.

Graetz, P., De Bleser, R., \& Willmes, K. (1992). Akense afasie test. Lisse: Swets \& Zeitlinger.

Han, Y. J., Sung, J. E., Kim, Y. H., \& Cheon, H. J. (2012). The effects of constraint-induced language therapy on language performance in Korean individuals with aphasia. Korean Journal of Communication Disorders, 17, 424-437.

Holland, A. (1989). Recovery in aphasia. In F. Boller \& J. Grafman (Eds.), Handbook of neuropsychology (vol. 2, pp. 83-90). Amsterdam: Elsevier.
Huber, W., Poeck, K., Weniger, D., \& Willmes, K. (1983). Aachener Aphasie Test. Göttingen: Hogrefe Verlag.

Kaplan, E. , Goodglass, H., \& Weintraub, S. (1983). Boston Naming Test. Philadelphia, PA: Lea \& Febiger.

Kaplan, E., Goodglass, H., \& Weintraub, S. (2001). Boston Naming Test (2nd ed.). Philadelphia, PA: Lippincott Williams \& Wilkins.

Kay, J., Lesser, R., \& Coltheart, M. (2009). PALPA : psykolingvistisk kartlegging av språkprosessering hos afasirammede [psycholinguistic assessment of language processing in aphasia]. Oslo: Novus forl.

Kertesz, A. (1982). The Western Aphasia Battery. New York, NY: Grune \& Stratton.

Kertesz, A. (1984). Recovery from aphasia. In F. C. Rose (Ed.), Progress in aphasiology (pp. 23-39). New York, NY: Raven Press.

Kertesz, A., \& McCabe, P. (1977). Recovery patterns and prognosis in aphasia. Brain, 100, 1-18.

Kim, H. H., \& Na, D. L. (1997). Korean Boston Naming Test. Seoul: Hakjisa.

Kim, H. H., \& Na, D. L. (2001). Korean version of Western Aphasia Battery $(K-W A B)$. Seoul: Paradise Welfare Foundation.

Kirmess, M., \& Lind, M. (2011). Spoken language production as outcome measurement following constraint induced language therapy. Aphasiology, 25, 1207-1238.

Kirmess, M., \& Maher, L. M. (2010). Constraint induced language therapy in early aphasia rehabilitation. Aphasiology, 24, 725-736.

Kleim, J. A., \& Jones, T. A. (2008). Principles of experience-dependent neural plasticity: implications for rehabilitation after brain damage. Journal of Speech, Language, and Hearing Research, 51, S225-S239.

Kurland, J., Pulvermüller, F., Silva, N., Burke, K., \& Andrianopoulos, M. (2012). Constrained versus unconstrained intensive language therapy in two individuals with chronic, moderate-to-severe aphasia and apraxia of speech: behavioral and fMRI outcomes. American Journal of Speech-Language Pathology, 21, S65-S87.

Maher, L. M., Kendall, D., Swearengin, J. A., Rodriguez, A., Leon, S. A., Pingel, K., ... \& Rothi, L. J. G. (2006). A pilot study of use-dependent learning in the context of constraint induced language therapy. Journal of the International Neuropsychological Society, 12, 843-852.

Marien, P., Mampaey, E., Vervaet, A., Saerens, J., \& De Deyn, P. P. (1998). Normative data for the Boston Naming Test in native Dutch-speaking Belgian elderly. Brain and Language, 65, 447-467.

Mark, V. W., Taub, E., \& Morris, D. M. (2006). Neuroplasticity and constraintinduced movement therapy. Europa Medicophysica, 42, 269-284. 
McNeil, M. R., \& Pratt, S. R. (2001). Defining aphasia: some theoretical and clinical implications of operating from a formal definition. Aphasiology, $15,901-911$.

Meinzer, M., Rodriguez, A. D., \& Rothi, L. J. G. (2012). First decade of research on constrained-induced treatment approaches for aphasia rehabilitation. Archives of Physical Medicine and Rehabilitation, 93(1 Suppl), S35-S45.

Meinzer, M., Streiftau, S., \& Rockstroh, B. (2007). Intensive language training in the rehabilitation of chronic aphasia: efficient training by laypersons. Journal of the International Neuropsychological Society, 13, 846-853.

Mohr, B., Difrancesco, S., Harrington, K., Evans, S., \& Pulvermüller, F. (2014). Changes of right-hemispheric activation after constraint-induced, intensive language action therapy in chronic aphasia. Frontiers in Human Neuroscience, $8,1-15$

Naeser, M. A., Martin, P. I., Treglia, E., Ho, M., Kaplan, E., Bashir, S., ... \& Pascual-Leone, A. (2010). Research with rTMS in the treatment of aphasia. Restorative Neurology and Neuroscience, 28, 511-529.

Nicholas, M., Obler, L., Albert, M., \& Goodglass, H. (1985). Lexical retrieval in healthy aging. Cortex, 21, 595-606.

Page, S. J., \& Wallace, S. E. (2014). Speech language pathologists' opinions of constraint-induced language therapy. Topics in Stroke Rehabilitation, 21, 332-338.

Poeck, K., Huber, W., \& Willmes, K. (1989). Outcome of intensive language treatment in aphasia. Journal of Speech and Hearing Disorders, 54, 471-479.

Pulvermüller, F., Hauk, O., Zohsel, K., Neininger, B., \& Mohr, B. (2005). Therapy-related reorganization of language in both hemispheres of patients with chronic aphasia. Neuroimage, 28, 481-489.

Pulvermüller, F., Neininger, B., Elbert, T., Mohr, B., Rockstroh, B., Koebbel, P., ... \& Taub, E. (2001). Constraint-induced therapy of chronic aphasia after stroke. Stroke, 32, 1621-1626.

Raymer, A. (2009). Constraint-induced language therapy: a systematic review. ASHA Leader, 14, 26-27.

Reinvang, I. (1985). Aphasia and brain organization. New York, NY: Plenum Press.

Reinvang, I., \& Engvik, H. (1980). Norsk grunntest for afasi - håndbok. Oslo: Universitetsforlaget.

Richter, M., Miltner, W. H., \& Straube, T. (2008). Association between therapy outcome and right-hemispheric activation in chronic aphasia. Brain, $131,1391-1401$

Rose, M. L. (2013). Releasing the constraints on aphasia therapy: the positive impact of gesture and multimodality treatments. American Journal of SpeechLanguage Pathology, 22, S227-S239.

Sickert, A., Anders, L. C., Münte, T. F., \& Sailer, M. (2014). Constraint-induced aphasia therapy following sub-acute stroke: a single-blind, randomised clinical trial of a modified therapy schedule. Journal of Neurology, Neurosurgery \& Psychiatry, 85, 51-55.

Szaflarski, J. P., Ball, A. L., Grether, S., Al-fwaress, F., Griffith, N. M., NeilsStrunjas, J., ... \& Reichhardt, R. (2008). Constraint-induced aphasia therapy stimulates language recovery in patients with chronic aphasia after ischemic stroke. Medical Science Monitor, 14, CR243-CR250.

Visintin, M., Barbeau, H., Korner-Bitensky, N., \& Mayo, N. E. (1998). A new approach to retrain gait in stroke patients through body weight support and treadmill stimulation. Stroke, 29, 1122-1128.

Wilssens, I., Vandenborre, D., van Dun, K., Verhoeven, J., Visch-Brink, E., \& Mariën, P. (2015). Constraint-induced aphasia therapy versus intensive semantic treatment in fluent aphasia. American Journal of Speech-Language Pathology, 24, 281-294. 


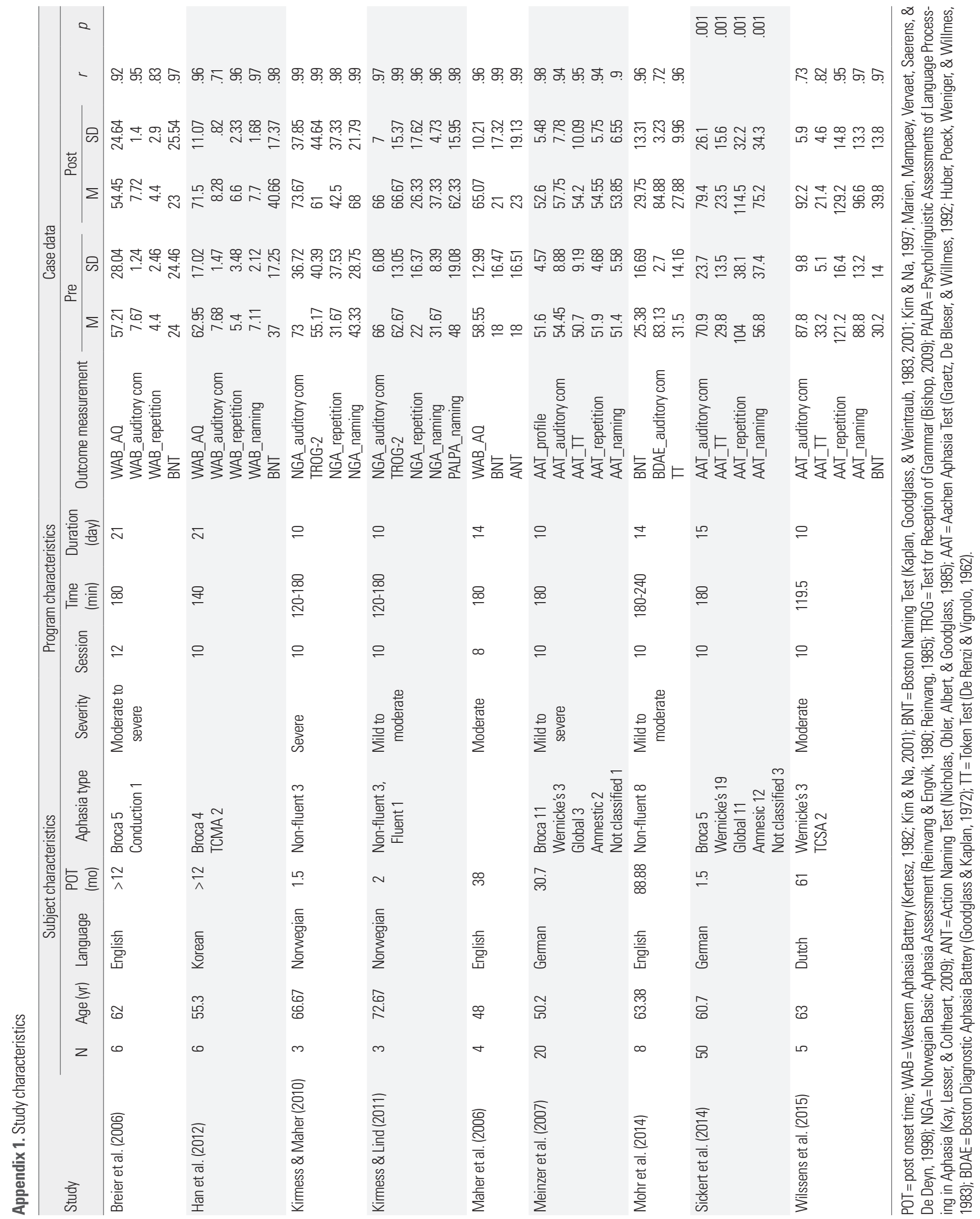




\section{국문초록}

\section{실어증 환자들을 위한 CILT 중재 효과에 대한 메타분석}

홍새미 ${ }^{12}$ - 강진경 ${ }^{2}$ 엄보라 $\cdot$ 김영태 ${ }^{2} \cdot$ 성지은 2 심현섭 2 정필연

${ }^{1}$ 서울아산병원 재활의학과, ${ }^{2}$ 이화여자대학교 언어병리학과

배경 및 목적: Constraint-Induced Language Therapy (CILT) 중재는 집중적인 일정 동안 구어를 극대화하여 사용할 수 있게 구조화 한 실어증 중재방법이다. 여러 연구들이 CILT 중재의 효과를 검증하였지만 상이한 연구결과가 혼재하였다. 이에 본 연구에서는 메타 분석을 통해 실어증 환자 대상으로 CILT 중재의 효과성을 보고한 개별 연구들의 결과를 종합하여 증거기반 실제를 구축하고자 하였 다. 방법: 총 5 개의 국내외 데이터베이스를 이용하여 실어증 환자를 대상으로 CILT 중재를 실시한 연구들 중 선정기준에 부합한 총 9편 의 문헌을 수집하였다. 그리고 중재에 따른 언어검사 결과를 종합하여 언어의 하위 영역 및 실어증 발병기간에 따른 효과크기를 각각 살펴보았다. 결과: CILT 중재는 실어증 환자의 전반적인 언어능력을 비롯하여 청각적 이해력, 따라 말하기, 이름대기 능력 향상에 유의 한 효과가 있는 것으로 나타났다. 또한 CILT 중재는 급성실어증과 만성실어증 환자의 전반적인 언어능력 및 모든 언어 하위 영역 향상 에서도 유의한 효과가 있는 것으로 나타났다. 논의 및 결론: 본 연구는 CILT 중재의 종합적인 효과 검증을 통해 CILT 중재가 발병기간 과 무관하게 실어증 환자의 전반적인 언어능력과 언어의 각 하위 영역을 향상시키는 데 효과적이라는 결과를 도출하였다. 이를 통해 CILT 중재에 대한 기존 연구들의 상반된 결과들을 통일하여 임상적 유용성을 제고하는 근거를 마련하였다.

핵심어: 실어증, CILT, 메타분석

본 연구는 2016년도 이화여자대학교 BK21 PLUS 사업의 지원을 받은 연구임.

\section{참고문헌}

김향희, 나덕렬(1997). 한국판 보스톤 이름대기 검사. 서울: 학지사.

김향희, 나덕렬(2001). 한국판 웨스턴 실어증 검사(K-WAB). 서울: 파라다이스복지재단.

한윤진, 성지은, 김연희, 전희정(2012). CILT 중재가 비유창성 실어증 환자의 구어의사소통능력과 정보 전달능력에 미치는 효과. 언어청각장애연구,

17, 424-437. 